\title{
APPLICATION OF STEAM TURBINES SIMULATION MODELS IN POWER GENERATION SYSTEMS
}

\author{
C.S.Bresolin, |ABSTRACT \\ P.S. Schneider, \\ The goal of this work is to simulate partial load operation of steam turbines in \\ H.A. Vielmo \\ different controlling modes. An isentropic efficiency function is associated to a \\ specific steam turbine. The Schegliáiev and the Stodola's Ellipse Law, relating \\ and F.H.R.França \\ levels of pressure with mass flow, are compared. The proposed operational modes \\ are: a) sliding pressure; b) throttling valve; c) nozzle valve. As a conclusion, \\ Schegliáiev and Stodola's models leads to very similar results and the operational \\ modes by valves establishes theoretical limits of operation for steam turbines. The \\ Universidade Federal do Rio Grande do Sul \\ sliding pressure control is more efficient considering design operation. \\ Departamento de Engenharia Mecânica \\ Rua Sarmento Leite, 425. \\ Keywords: steam turbines, partial loads, isentropic efficiency, Stodola's Ellipse \\ Law, nozzle analogy \\ 90050-170 Porto Alegre RS \\ cirilobresolin@hotmail.com \\ pss@mecanica.ufrgs.com.br \\ vielmoh@mecanica.ufrgs.br \\ frfranca@mecanica.ufrgs.br
}

\section{NOMENCLATURE}

$\begin{array}{ll}h & \text { specific enthalpy, } \mathrm{kJ} / \mathrm{kg} \\ k & \text { isentropic coefficient } \\ \dot{m} & \text { mass flow rate, } \mathrm{kg} / \mathrm{s} \\ P & \text { pressure, } \mathrm{kPa} \\ T & \text { temperature, } \mathrm{K} \\ v & \text { specific volume, } \mathrm{m}^{3} / \mathrm{kg} \\ \dot{W} & \text { generated power, } \mathrm{kW}\end{array}$

\section{Greek symbols}

$\phi \quad$ flow constant coefficient

$\eta \quad$ isentropic efficiency

$\sigma \quad$ critical steam pressure ratio

\author{
Subscripts \\ 1 inlet \\ 2 outlet \\ $D$ design condition \\ $i \quad$ group number
}

\section{INTRODUCTION}

A constant challenge for simulation tool of thermal systems is to predicting partial loads behaviors. Economic viability of a given system strongly depends on the efficiencies of different devices and equipments, and its final behavior is not always predictable. Similar devices have their maximal loads limited to the point of maximal efficiency, as with steam turbines and cogeneration generators, even if these equipments could deliver more power in less efficient range of operation.

Sizing of the complete system must satisfy two situations: the maximum load that the plant can produce, namely the design condition, and its lower limit. In
Rankine type cycles applied to thermoelectrical power plants, this lower limit usually goes down to 50 to $60 \%$ of the design load, called partial load.

Steam turbines are one of the main components in such systems, since they are driving devices and its behavior is strongly coupled to many variables of the plant. Different strategies of control are used in order to take into account the many levels of steam bleedings to preheaters, regenerators and auxiliary systems.

The motivation of this paper is to discuss simulation models to turbines running at different loads. These models will be in a next step integrated to simulation codes of power generation plants. Models widely known in literature are presented here, as the constant isentropic efficiency (Van Wylen et al, 1995), nozzle analogy of Schegliáiev (1978), and Stodola's Ellipse Law (Cooke, 1985). These modes are often used in simulation tools, as IPSEPro (Simtech, 2000) and GateCycle (Enter Software Inc., 1995), among others. Control strategies in partial load operation will be also discussed here, applied to a study case of power generation. A four-group turbine will be simulated considering a variable loads and different operative conditions of the steam generator.

\section{TURBINE EFFICIENCY}

Working fluid expansion throughout a steam turbine is usually represented by the isentropic efficiency $\eta$, witch corrects the generated power $\dot{W}[\mathrm{~kW}]$ of an ideal, adiabatic and frictionless expansion, as follows:

$$
\dot{W}=\sum_{i=1}^{n} \eta_{i} \dot{m}_{i}\left(h_{1 i}-h_{2 s i}\right)
$$

where $\dot{m}_{i}$ is the steam mass flow rate $[\mathrm{kg} / \mathrm{s}], h_{l}$ and $h_{2 s}$ are, respectively, the inlet and outlet specific enthalpies $[\mathrm{kJ} / \mathrm{kg}]$ of each group $i$, from a total number $n$ of groups of the 
turbine, and $h_{2 s}$ is the specific enthalpy of a isentropic expansion. The isentropic efficiency $\eta_{i}$ of each group is defined by the following rate of enthalpy differences:

$$
\eta=\frac{h_{1}-h_{2}}{h_{1}-h_{2 s}}
$$

The isentropic efficiency takes into account leakages and friction losses, pressure drop due to the steam flow across the equipment, heat exchanges to the environment, etc. All this losses can be modeled in details, but this is particularly interesting during the design development of a turbine, when some special effects can be worked out. Nevertheless, isentropic efficiency is an useful option when the goal is to simulate the behavior of a turbine, for it takes into account all the above effects, and is used by all models presented in this paper.

Simpler models assume a constant value to the isentropic efficiency, to employ for both demanded loads and operational steam pressures. Actually, this efficiency varies with (Fig. 1).

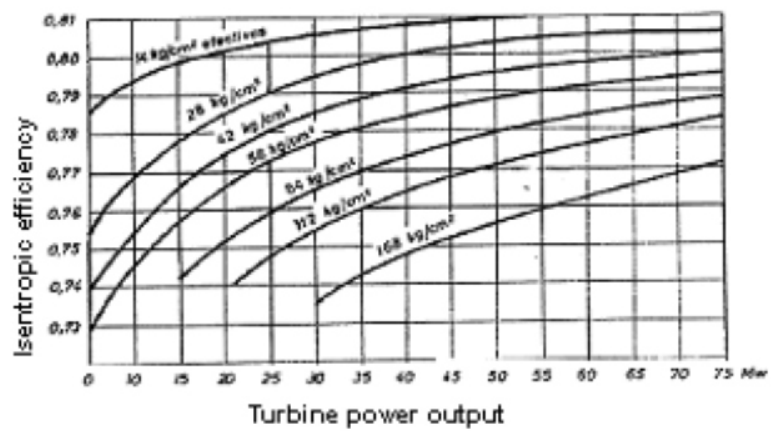

Figure 1. Turbine isentropic efficiency according to different working loads and steam inlet pressures

[Fonseca, 2003]

Condensation turbines work in a range of steam states, where the limits are: inlet, with temperature and pressure coupled to the steam generator, and outlet, where the steam state depends on the condenser conditions. As this last condition can be taken as a parameter to be achieved, it is always worthwhile keeping inlet steam temperature constant as high as possible, since the temperature difference determinates theoretically the cycle efficiency.

Concerning electrical generation, where the turbine speed is always kept constant, load variation is obtained usually by changes in the steam mass flow rate (Gill, 1984). After all the restrictions above discussed, the inlet steam pressure turns up to be the control variable of the process. In fact, lowering the steam pressure at the inlet of the turbine will lead to the same behavior in all turbine groups. Predicting pressure levels in partial loads is the goal of all models that will be present in this paper.

\section{SCHEGLIÁIEV MODEL}

This model proposes a relation between the steam mass flow rate and the rate of inlet and outlet steam pressures for the partial load and the design condition (Paz, 2002). Based on the nozzle flow analogy, Schegliáiev (1978) developed an expression for the partial load operation that relates the steam mass flow rate $\dot{m}[\mathrm{~kg} / \mathrm{s}]$, steam pressures $P[\mathrm{kPa}]$ and steam temperatures $T[\mathrm{~K}]$ :

$$
\frac{\dot{m}}{\dot{m}_{D}}=\sqrt{\frac{\left(P_{1}^{2}-P_{2}^{2}\right)-\sigma\left(P_{1}-P_{2}\right)^{2}}{\left(P_{1 D}^{2}-P_{2 D}^{2}\right)-\sigma\left(P_{1 D}-P_{2 D}\right)^{2}}} \sqrt{\frac{T_{1 D}}{T_{1}}}
$$

Index D refers to design conditions, while indices 1 and 2 are relative to inlet and outlet of each turbine group, respectively. Dimensionless factor $\sigma$ expresses a ratio related to the critical steam pressure

$$
\sigma=\frac{\varepsilon_{*}}{1-\varepsilon_{*}} \text { with } \varepsilon_{*}=\left(\frac{2}{k+1}\right)^{\frac{k}{k+1}}
$$

and $\varepsilon_{*}$ depends on $k$, the isentropic coefficient.

Still according to Schegliáiev, $\varepsilon_{*}$ is less than 0.3 for condensation turbines with a very large number of stages, and terms like $\sigma\left(P_{1}-P_{2}\right)^{2}$ and $\sigma\left(P_{1 D}-P_{2 D}\right)^{2}$ can be neglected in Eq. (3). Also, outlet steam pressure $P_{2}$ is much smaller than the inlet steam pressure, so this equation reduces to:

$$
\frac{\dot{m}}{\dot{m}_{D}}=\frac{P_{1}}{P_{1 D}} \sqrt{\frac{T_{1 D}}{T_{1}}}
$$

If $\varepsilon_{*}=\varepsilon_{\text {crit }}<0.3$, Eq. (5) is valid for any range of steam pressure, otherwise, Eq. (3) must be used instead, and $P_{2} / P_{1}>\varepsilon_{\text {crit }}$.

\section{STODOLA'S ELLIPSE LAW}

Cooke (1985) discusses this law when applied to non-controlled expansion processes in turbines. It's an empirical model, where a flow constant coefficient $\phi$ is defined as

$$
\phi=\frac{\dot{m}}{\sqrt{P / v}}
$$

where $P$ is the total inlet pressure $[\mathrm{kPa}]$ and $v$ is the specific volume $\left[\mathrm{m}^{3} / \mathrm{kg}\right]$. This model is based on the assumption that multi-stages groups with non-controlled expansions can be seen as analogous to a single nozzle. The Stodola's ellipse is a relation where the flow constant coefficient of a given group $i$ is

$$
\phi_{i} \propto \sqrt{1-\left(\frac{B_{i}}{P_{i}}\right)^{2}}
$$

$B_{\mathrm{i}}$ is the steam static pressure $[\mathrm{kPa}]$ at the turbine hose, just before the steam extraction and $P_{i}$ is the steam total pressure $[\mathrm{kPa}]$ in the inlet of each group. This relation was first developed for group with a very large number of stages, but it was experimentally verified for as few stages as 8 , with $50 \%$ reaction. The proportion in the former expression can be eliminated, as follows.

$$
\frac{\phi_{i}}{\phi_{i d}}=\sqrt{1-\left(\frac{B_{i}}{P_{i}}\right)^{2}} / \sqrt{1-\left(\frac{B_{i D}}{P_{i D}}\right)^{2}}
$$


Algebraically rearranging this equation in regard to $P$,

$$
P_{i}=\frac{B_{i}}{\sqrt{1-\phi_{i}^{2} Y_{i D}}}
$$

Finally, the so-called Stodola's constant $Y_{i D}$ is defined as

$$
Y_{i D}=\left(P_{i D}^{2}-B_{i D}^{2}\right)\left(P_{i D}^{2} \phi_{i D}\right)
$$

witch is the same to all loads.

Flow coefficients $\phi_{I}$ and $\phi_{i D}$ follow Eq.(6). Cooke (op cit) suggests that a fairly good approximation is obtained by taking the steam static pressure $B_{i}$ at the outlet of a given group as the inlet steam pressure of the next one $P_{i+1}$.

\section{TURBINE OPERATION AND LOAD CONTROL}

Equations 11 to 14 represent the problem to be solved. Eq. 11 expresses the load $W$, Eq. 12 generically states a relation between steam flow rate and pressure calculated by ether Schegliáiev's or Stodola's models. Eq. 13 is a fitting curve of turbine isentropic efficiency (Fig. 1 and Fig. 3, as seen later in the text). Finally, Eq. 14 closes the system.

$$
\begin{gathered}
\dot{W}=\eta \dot{m}\left[h_{1}\left(P_{1}, T_{1}\right)-h_{2}\left(P_{2}, T_{2}\right)\right] \\
\dot{m}=f\left(P_{1}, T_{1}\right) \\
\eta=f(\dot{m}) \\
\eta=\frac{h_{1}\left(P_{1}, T_{1}\right)-h_{2}\left(P_{2}, T_{2}\right)}{h_{1}\left(P_{1}, T_{1}\right)-h_{2 s}\left(P_{2}, s_{1}\right)} \text { where } s_{1}=f\left(P_{1}, T_{1}\right)
\end{gathered}
$$

It can be seen that the generated power $W$ depends on the steam flow rate and its change in enthalpy. Furthering addition, the amount of steam is a function of the steam pressure drop between the inlet and outlet. Change in enthalpy also depends on the steam pressure drop and its temperature. As steam state at the outlet of the turbine is linked to the environmental conditions, and as usually the inlet steam temperature is kept as high as possible to achieve maximum cycle efficiency, the only quantity left for load control is the inlet steam pressure, which can modulate the steam flow rate.

Different systems are employed in order to perform variable loads in turbines: a) full arc throttling, where valves restrict both steam flow rate and pressure; b) partial arc throttling, with a set of sequential valves that modulate the steam flow rate into the nozzles of the fist stage of the turbine; c) sliding pressure, where steam flow rate and pressure are operated by the steam generator and the main feed pump, and ; d) additional steam inlet into stages other than the first one, allowing overload delivery.

Full arc and partial arc throttling are able to sustain constant steam pressure in the steam generator in variable load regimes, but both lead to a drop in the steam temperature due to its expansion, reducing cycle efficiency. Sliding pressure control becomes interesting because steam temperature remains constant in partial load regimes.

Engenharia Térmica (Thermal Engineering), Vol. 5 - No 01 - July 2006
These three modes of control can be simulated with the set of equations formerly presented. Sliding pressure is the simpler alternative to reproduce, since the inlet steam temperature $T_{1}$ is prescribed. In the full arc throttling alternative, specific enthalpy $h_{l}$ in Eqs. 11 and 14 becomes a parameter of the problem because the expansion is assumed to be isenthalpic. Finally, partial arc throttling alternative needs a prescribed value of the specific entropy $s_{1}$.

Thermodynamic properties were calculated after the IAPWS-IF97 formulation (Wagner et al, 2000) and subroutines were written in FORTRAN90 by Fonseca and Schneider (2004).

\section{SIMULATED MODEL}

In order to test the three control alternatives, a situation were a four-group turbine (Fig. 2) with reheating and two bleedings is proposed.

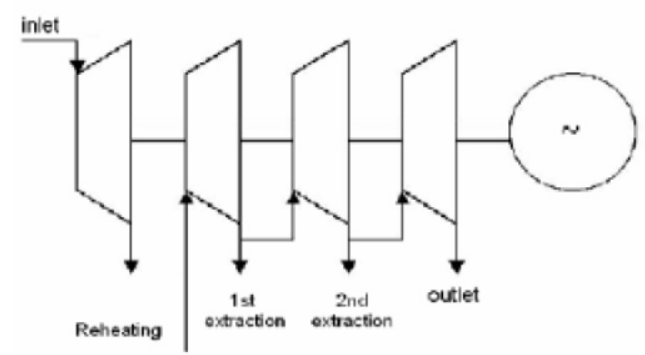

Figure 2. Schematic view of the four-group turbine with reheating and two extractions

Running at design conditions, this turbine generates $160 \mathrm{MW}_{\mathrm{e}}$, with an inlet steam pressure of $18 \mathrm{MPa}$ at $530^{\circ} \mathrm{C}$. Condenser operates at $0.02 \mathrm{MPa}$ in the steam side, according to a given environmental condition. If the isentropic efficiency is taken identically as 0.8 (Fig. 3) for all four groups, steam flow rate is $130.8 \mathrm{~kg} / \mathrm{s}$. In the reheating circuit, steam temperature is raised up to the same level as the inlet steam in the first group. Steam flow rate in both extractions represents $8 \%$ of the group flow rate. Load was varied from $40 \%$ up to $100 \%$, even considering that $50 \%$ partial load is the inferior limit practiced in most commercial plants due to the lost of efficiency and other practical problems. It's also assumed that the outlet steam state of a certain group will be taken as the inlet state for the next one. All data presented here are considered design conditions, and will be the basis to partial load simulation. Isentropic efficiencies in partial load were estimated with the help of fitting curves (Fig. 3) and data from Fig. 1.

A FORTRAN90 code was specially built using the non-linear subroutine $D N E Q N F$ from the IMSL library.

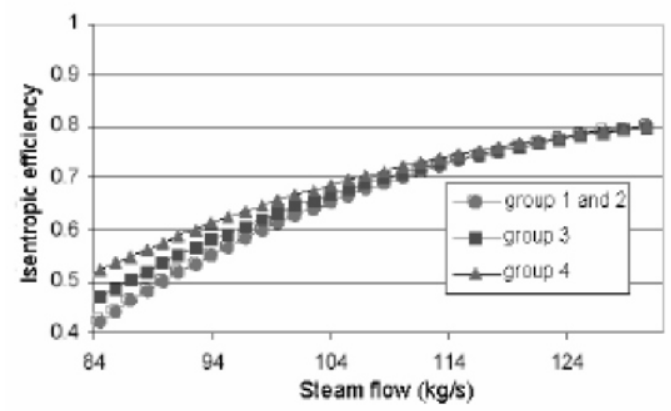

Figure 3. Adjusted isentropic efficiency curves in respect to steam mass flow rate 


\section{RESULTS}

The first relevant results concern the steam pressure behavior at turbine inlet in partial load operation, following a sliding pressure strategy of control (Fig. 4). Data from both Schegliáiev's and Stodola's models were very close. Maximum bias of $2 \%$ was observed at very low partial loads, which suggests that both models can be employed indistinctly. Schegliáiev's model was chosen to run all simulation cases because it achieves convergence more easily.

Both models display a linear behavior, as can be seen by inspecting Eq. 3, from Schegliáiev's model. Simulation results show that the difference $\left(P_{1}-P_{2}\right)$ is very close to $\left(P_{I D}-P_{2 D}\right)$ for all groups. As the steam inlet temperature $T_{l}$ is kept constant, the non-linear terms repeat a constant proportion for different loads.

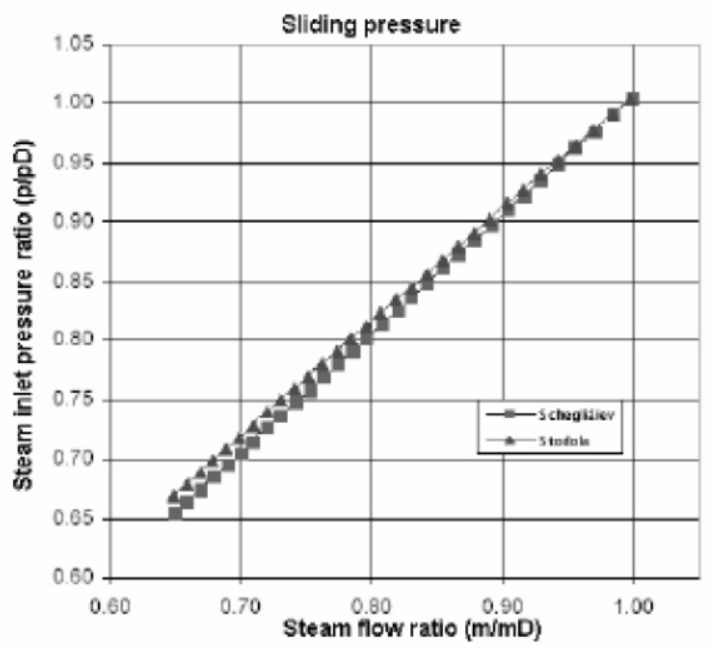

Figure 4. Relation between steam inlet pressure and steam mass rate

Figure 5 shows the behavior of the steam inlet pressure for different strategies of load control.

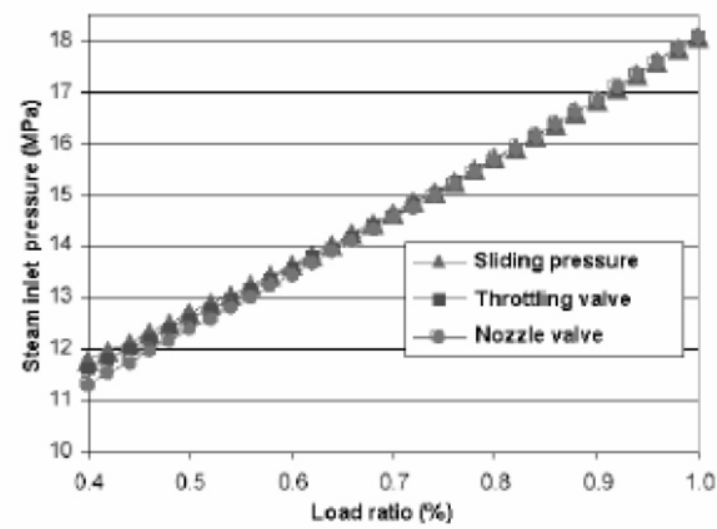

Figure 5. Steam inlet pressure as a function of load for three strategies for control solved as obtained from Schegliáiev's model.

The simulation code directly finds the desired steam inlet pressure when running in sliding pressure control strategy, always keeping constant the steam inlet temperature. When the same procedure is performed to partial arc throttling, the calculated steam inlet pressure is slightly smaller that the one found by sliding pressure. This happens because steam temperature show a slight decay due to the throttling in partial load, and the corresponding power reduction must be compensated by an increase of the steam mass flow rate. As with the former control strategy, partial loads present an almost linear behavior, only perturbed close to small load conditions.

Figure 6 shows the variation in steam inlet temperature for different loads. This temperature is kept constant in sliding pressure control, but always shows a small reduction in arc throttling, specially in partial arc.

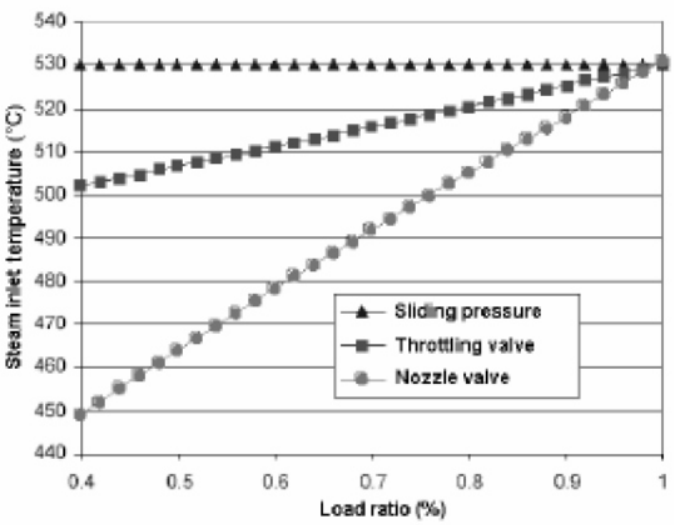

Figure 6. Steam inlet temperature for a range of load operation.

Figure 7 presents the steam temperature evolution at the turbine discharge. There is a level augmentation in the opposite direction of the load variation.

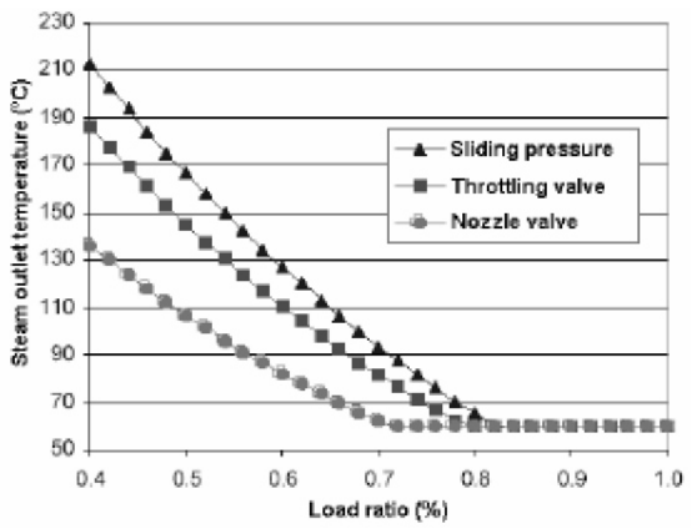

Figure 7. Steam temperature behavior at the exhaust of the turbine for different load values

This process can be seen in the T-s diagram of Figure 8, where steam at partial loads expands in lower pressures than of the design condition. In order to control steam temperature increase, water injectors is often used to avoid the admission of superheated steam in the condenser, which is placed right after the turbine.

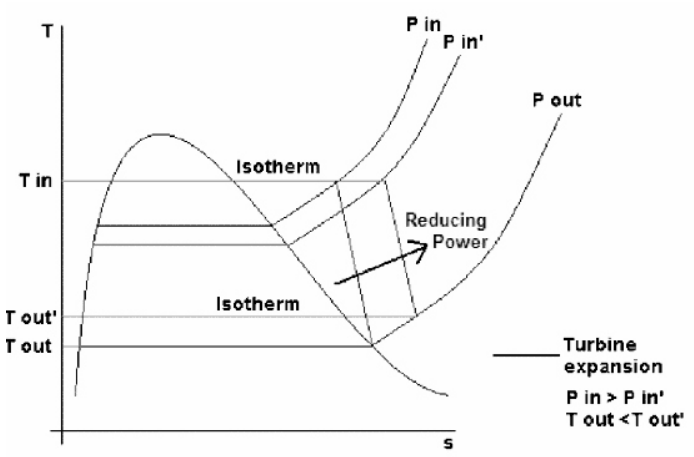

Figure 8. T-s diagram for two expansion processes of steam at the exhaust of a turbine. 
It is worth to notice that partial arc throttling is modeled as isentropic, with $\eta=1$, but full arc throttling is isenthalpic, with isentropic efficiency $\eta=0$. Both represent ideal situations, and their respective results express theoretical limits. Actually, their results might assume values close to each other, since the process efficiencies probably are in an intermediate position.

Figure 9 shows the thermal efficiency of a Rankine cycle with a turbine that is the same as the one presented in this paper.

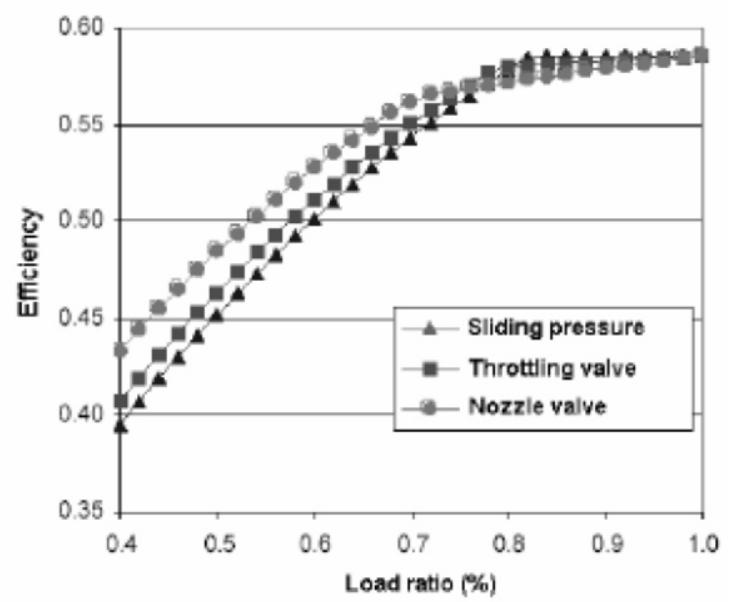

Figure 9. Thermal efficiency of a Rankine cycle for three strategies of load control.

For load rates under $75 \%$, the cycle would be better controlled by partial arc throttling, but sliding pressure seems to be more efficient for load rates over $80 \%$. Also, total arc throttling appears to be more interesting for the intermediate range. As the two throttling modes represent theoretical limits, it can be stated that they fit better whenever outlet steam is superheated, and sliding pressure is more interesting for saturated conditions.

\section{CONCLUSIONS}

This paper synthesizes a simulation model for steam turbines operating over partial load conditions.

Inlet steam pressure for all groups is calculated by two different models, available in literature. The Schegliáiev's and Stodola's models, where pressure is a function of mass flow rate, present very similar results, even if the first one has a more theoretical approach and the second is an empirical model.

Simulation for different load control modes enabled the reproduction of temperature and pressure variations for inlet and outlet flows. The assumption of isentropic efficiency for total arc throttling and isenthalpic efficiency for partial arc throttling led to the definition of limiting cases of operation.

A cycle efficiency analysis also showed that throttling strategy of control is more convenient when the outlet steam is superheated, corresponding to low partial loads, but sliding pressure control is better adapted to variable loads close to the design condition.

\section{ACKNOWLEDGMENTS}

The authors thank the financial support of $A N E E L$ to CGTEE-UFRGS Project 4, 2003-2004, as well as to all the engineering and technical team of CGTEE. First author would like to gratefully acknowledge the financial support of $C N P q$

\section{REFERENCES}

Cooke, D. H., 1985, On Prediction of Off Design Multistage Turbine Pressure by Stodola's Ellipse. Trans. ASME, Journal of Engineering for Gas Turbines and Power, 107, pp. 596606.

Enter Software Inc., 1995 "Gate Cycle", User's Guide, Merlo Park, USA.

Fonseca Jr., J. G., 2003, Análise Energética e Exergética de um Ciclo Rankine com Aquecimento Distrital: Estudo de uma Planta Termoelétrica, Master Thesis, Universidade Federal do Rio Grande do Sul PROMEC, Porto Alegre.

Fonseca Jr, J.G. and Schneider, P.S., 2004, Comparative Analysis of the IAPWS-IF97 Formulation Performance for Thermodynamic Properties of Water on a Rankine Cycle. RETERM - Thermal Engineering, $N^{\circ} 5$, pp 52-55.

Gill, A.B., 1984, Power Plant Performance. Butterworths and Co (Publishers) Ltd

Wagner, W., Cooper, J. R., Dittmann, A., Kijima, J., Kretzschmar, H. J., Kruse, A., Mares, R., Ogushi, K., Sato, H., Stöcker, I., Sifner, O., Takaishi, Y., Trübenbach, J., Willkommen, Th., 2000, IAPWS Industrial Formulation 1997 for the Thermodynamic Properties of Water and Steam. Journal of Engineering for Gas Turbines and Power - ASME, Vol 122, pp 150 - 182.

Paz, A.E.C., 2002, Simulação de Sistemas Térmicos de Potência para Geração de Energia Elétrica. Master Thesis, Universidade Federal do Rio Grande do Sul - PROMEC, Porto Alegre. Moscou.

Schegliaiev A.V., 1978, Turbinas de Vapor, Mir,

Simtech, 2000, “IPSE Pro Process Simulator”, User Documentation: Programa Modules and Model Libraries, Simtech Simulation Technology

(www.simtechnology.com)

Van Wylen, G., Sonntag, R., e Borgnakke, C., 1995, Fundamentos da Termodinâmica Clássica, Editora Edgard Blücher Ltda., São Paulo. 